\title{
EDITORIAL
}

nature

cell biology

\section{Missing the boat: a loophole in start-up funding?}

\section{Funding agencies have set up dedicated schemes to help the plight of young principal investigators. But is the playing field level for all qualified scientists?}

In many countries it is possible to obtain one's first position as principal investigator within five years of a first postdoc, and funding policies that encourage this fast-track route are all the rage. In the UK, for example, the Medical Research Council and the Wellcome Trust offer generous Career Development Awards of up to $£ 1$ million - enough to effectively kickstart a successful independent career. However, both specify a narrow time-frame (three to six years' postdoctoral experience), which markedly restricts the number of candidates. This reflects the international funding landscape; for example, in Germany the 'Junior Professor' scheme is also capped at nine years of postgraduate research.

Some of the most promising candidates who follow a less linear career path run the risk of disqualifying themselves from vital funding. An investigator who has gone through multiple postdocs to learn different skills in diverse disciplines may be better equipped for innovative and independent research than fast-track, inexperienced principal investigators. Clearly, it is good to encourage early independence, but not at the expense of researchers who delay the move for the right reasons. Such principal investigators may actually find themselves between a rock and a hard place: they may have been awarded a coveted university position but be unable to apply for start-up funding and have to compete for programme grants with senior researchers who have established groups of a dozen people.

The difficulties experienced in the first round of funding by the European Research Council (ERC) highlight this potential problem. The ERC was set up by the European Union with the brief to fund the best basic research. Proposals are judged by scientists and awarded on the basis of quality, irrespective of nationality. For its first round of awards, the ERC dedicated its entire budget to 'Starting Grants' for young scientists (that is, anyone holding a $\mathrm{PhD}$ for two to nine years). The number of applicants far exceeded expectations and less than 3\% were succesful. For the Molecular, Cellular and Developmental Biology panel, 18 of 720 applicants received the $€ 1$ million award (as of February 2008). Panel member Kai Simons (Max Planck Institute, Dresden) comments that "one of the missions of the ERC is to set up a 'European Label of Scientific Quality' so that it can aim to double its budget for the next framework in 2013". Only then can the award rate match the demand in a more reasonable way. For now, each panel has had to make tough decisions as to how to allocate the available funding. The stated aim of the scheme is to help researchers to start their own laboratories. However, given the sheer number of candidates, young principal investigators with established independent groups and several senior-author publications, stood a better chance. For example, only $25 \%$ of the Molecular, Cellular and Developmental Biology awards went to candidates who have had their own laboratory for less than two years; $75 \%$ of the successful applicants had already published at least two papers as senior author. From 2009, applications will be restricted to scientists with three to eight years of postdoctoral experience, a limit selecting for 'freshly minted' principal investigators. Nevertheless, it could still penalize seasoned postdocs just starting their group if they have to compete with established principal investigators solely on the basis of publication record.

Some organizations have taken heed of this problem and moved away from using the number of postdoctoral years to assess eligibility for start-up funding. The EMBO Young Investigator Programme was among the first to do so. Gerlind Wallon, who runs the programme, says that "the scheme provides a prestige label to successful young scientists: it only offers limited financial support, but it is widely recognised for its networking possibilities". After referees voiced the concern that it was unfair to judge candidates about to start their groups against those with four years' experience as independent investigators, the programme changed its definition of a young principal investigator. This is now defined as a scientist who has had an independent group for one to four years (extensions can be offered for parenting or military breaks) and at least one senior-author paper. In the UK, the Royal Society's 'University Research Fellow' scheme used to also have a post- $\mathrm{PhD}$ time limit, which has recently been abandoned in favour of 'being at an early- to midcareer stage, for example, applicants can have had between one and three postdoctoral positions'. The Spanish Science and Innovation Ministry does consider first-time applicants for a project grant in a separate category, independently of their years of postdoctoral experience, but they specify that applicants must be under forty years of age. In the USA, young principal investigators starting as tenure-track assistant professors often have an advantage over their European counterparts, as universities usually offer attractive start-up packages. Still, funding restrictions have made long-term funding much harder to acquire. This month, in an attempt to fill the uncertainty before the first NIH R01, the Howard Hughes Medical Institute launched the 'Early Career Scientist Competition', an award specifically designed for principal investigators holding tenure-track positions for two to six years.

Would a similar definition as that of Howard Hughes work for European schemes? One concern raised by Kai Simons is that the lack of a coherent career structure in Europe, and the absence of transparent tenure-track in many countries, would make it difficult to define when candidates are eligible. Gerlind Wallon agrees that assessing when applicants hold a truly independent position can be difficult but adds that having scientists from different European countries on the evaluation panel can help. Perhaps these disparities mean that the problem of funding for new principal investigators with long postdoctoral experience can only be dealt with by each national government rather than at the European level. However, it is hard to imagine that most European countries would be willing to match the $€ 1$ million that the ERC earmarks for a successful start to an independent career.

To fund the most promising new independent investigators in Europe, schemes should separately evaluate postdocs, newly, and more established, principal investigators. Moreover, the laudable drive towards early independence should not penalize those aiming for scientific maturity before rising to the challenge of leading an independent research group.

Further reading at http://connotea.org/user/ncb/tag/startup\%20funding

Comments welcome on: http://tinyurl.com/6kx5nz 